\title{
EL SEGURO Y LAS GARANTÍAS POR IMPAGO DE RENTAS EN LOS ARRENDAMIENTOS DE LOCAL DE NEGOCIO EN TIEMPOS DE PANDEMIA (COVID-19)
}

\section{INSURANCE AND GUARANTEES FOR NON-PAYMENT OF RENTS IN LEASES OF BUSINESS PREMISES IN TIMES OF PANDEMIC (COVID-19)}

\author{
FÉLIX BENITO OSMA* \\ Fecha de recepción: 30 de abril 2020 \\ Fecha de aceptación 15 mayo 2019 \\ Disponible en línea: 30 de junio 2020
}

Para citar este artículo/To cite this article

Benito Osma, Félix. El seguro y las garantías por impago de rentas en los arrendamientos de local de negocio en tiempo de pandemia (COVID-19), 52 Rev.Ibero-Latinoam.Seguros, 37-52

(2020). https://doi.org/10.11144/Javeriana.ris52.sgir

doi: 10.11144/Javeriana.ris52.sgir

\footnotetext{
* Doctor en Derecho. Profesor de Derecho Mercantil y Derecho de Seguros en la Facultad de Ciencias Jurídicas y en la Escuela de Postgrado de la Universidad Carlos III de Madrid (España). Abogado del Ilustre Colegio de Abogados de Madrid. Secretario General de SEAIDA (Sección española de la Asociación Internacional de Derecho de Seguros). Miembro del Consejo de Presidencia de AIDA Mundial. Correo electrónico felix.benito.osma@uc3m.es; https://fbenitosma.blogspot.com/.
} 


\section{RESUMEN}

Con el este trabajo se pretende reflexionar sobre el impacto de la alarma sanitaria derivada de la declaración de pandemia (COVID-19) en los contratos de arrendamientos de local de negocio, así como en los seguros y garantías vinculados directa o indirectamente al arrendamiento como a la actividad comercial.

Palabras clave: arrendamiento de local de negocio, pago de la renta, seguros, garantías, aval, cláusula penal.

\section{ABSTRACT}

This paper reflects on the business lease contracts with the health alarm (COVID-19). The impact on insurance coverage linked to leasing contracts.

Keywords: business lease contracts, insurance, endorsement, guarantee, penalty clause.

\section{SUMARIO}

1. Introducción 2. La moratoria automática y el aplazamiento extraordinario, a falta de pacto, en el pago de la renta de los arrendatarios. 3. Los remedios al incumplimiento en el Derecho y en la jurisprudencia vigente. 4. Las consecuencias del incumplimiento del pago de la renta del arrendatario. 5. Los seguros en los contratos de arrendamiento de local de negocio. 6. El aval bancario. 7. Las cláusulas penales. 8. Consideraciones finales. 9. Bibliografía. 


\section{INTRODUCCIÓN}

Con el estado de alarma declarado ante la emergencia sanitaria derivada del COVID-19 ${ }^{1}$ se suspendió la apertura al público de los locales y de los establecimientos minoristas, a excepción de los establecimientos comerciales minoristas de alimentación, bebidas, productos y bienes de primera necesidad, establecimientos farmacéuticos, sanitarios, centros o clínicas veterinarias, ópticas y productos ortopédicos, productos higiénicos, prensa y papelería, combustible para la automoción, estancos, equipos tecnológicos y de telecomunicaciones, alimentos para animales de compañía, comercio por internet, telefónico o correspondencia, tintorerías, lavanderías y el ejercicio profesional de la actividad de peluquería a domicilio.

En las últimas fechas se ha iniciado un Plan flexible de reducción y desescalada gradual de las medidas restrictivas y reductoras de los derechos y libertades a la ciudadanía, a la sociedad y a la empresa ${ }^{2}$, siempre preservando la salud pública, con la finalidad de una recuperación paulatina de la vida cotidiana y de la actividad económica, minimizando el riesgo que representa el virus para la salud de la población.

\section{LA MORATORIA AUTOMÁTICA Y EL APLAZAMIENTO EXTRAORDINARIO, A FALTA DE PACTO, EN EL PAGO DE LA RENTA DE LOS ARRENDATARIOS}

La falta de ingresos o la minoración de los mismos durante el periodo que dure el estado de alarma puede dar lugar a la incapacidad financiera de autónomos y de pymes $^{3}$ para hacer frente al cumplimiento, total o parcial, de sus obligaciones de pago de renta de locales en alquiler que pone en serio riesgo la continuidad de sus actividades. Téngase en cuenta que se suspendió la apertura y que ahora está en mínimos, que incluso algunos de ellos todavía no han podido comenzar la apertura por cuanto que se han establecido unas medidas protocolos de prevención de los riesgos de seguridad e higiene al que han de cumplir los titulares de actividades económicas ${ }^{4}$.

\footnotetext{
1 Real Decreto 463/2020, de 14 de marzo, con prórroga (5 $5^{\text {a }}$ hasta el 7 de junio 2020 (Resolución de 20 de mayo, del Congreso de los Diputados, por el que se ordena la publicación del Acuerdo de autorización de la prórroga del estado de alarma declarado).

2 Orden SND/386/2020, de 3 mayo, por el que se flexibilizan determinadas restricciones sociales y se determinan las condiciones de desarrollo de la actividad de comercio minorista y de prestación de servicios, así como de las actividades de hostelería y restauración en los territorios menos afectados por la crisis sanitaria ocasionada por el COVID-19 (BOE núm. 123, de 3 de mayo). Actualmente, derogada por la Orden $\mathrm{SND} / 399 / 2020$, de 9 de mayo, para la flexibilización de determinadas restricciones de ámbito nacional, establecidas tras la declaración del estado de alarma en aplicación de la fase 1 del Plan para la transición hacia una nueva normalidad (BOE núm. 130, de 9 de mayo).

3 En la Exposición de Motivos del Real Decreto-Ley $N^{\circ}$ 15/2020 que como consecuencia del estado de alarma "muchas actividades económicas se han visto obligadas a suspender su actividad o a reducir drásticamente la misma", lo que puede dar lugar a una incapacidad financiera para hacer frente a sus obligaciones de pago de renta, poniendo en "serio riesgo la continuidad de sus actividades".

${ }^{4}$ Sin perjuicio de las medidas generales de seguridad e higiene para la prevención consistente en el mantenimiento de una distancia mínima de dos metros o medidas alternativas de protección física, de higiene de
} 
Mediante el RDL 15/2020, de 21 de abril ${ }^{5}$, ante la incertidumbre generada por el cierre temporal de las empresas, especialmente, para las pymes a los titulares de las actividades económicas como a los propios arrendadores "procede prever una regulación especifica en línea con la cláusula rebus sic stantibus, de elaboración jurisprudencial, que permite la modulación o modificación de las obligaciones contractuales si concurren los requisitos exigidos: imprevisibilidad e inevitabilidad del riesgo derivado, excesiva onerosidad de la prestación debida y buena fe contractual.

Se considera conveniente ofrecer una respuesta que permita abordar esta situación y regular un procedimiento para que las partes puedan llegar a un acuerdo para la modulación del pago de las rentas de los alquileres de locales"'.

De este modo, disciplina un régimen jurídico diferente para los contratos de arrendamiento con grandes tenedores ${ }^{7}$ y con otros arrendadores que no respondan a esta condición cualificada y cuantitativa.

manos y etiqueta respiratoria, se adoptan otras específicas exigibles a los establecimientos y locales con apertura al público en protección de los trabajadores y de la clientela.

El titular de la actividad económica debe cumplir la legislación vigente de prevención de riesgos laborales, tanto general como la específica para prevenir el contagio de COVID-19.

Y, además asegurará el cumplimiento de las siguientes medidas específicas de prevención respecto a todo su personal empleado y en cualquier zona común:

1. Tenencia de equipos individuales de protección adecuados al nivel de riesgo

2. Tener a disposición permanentemente geles hidroalcohólicos con actividad virucida autorizados y registrados por el Ministerio de Sanidad para la limpieza de manos o cuando no sea posible, agua y jabón. 3. Uso obligatorio de mascarillas cuando no pueda garantizarse la distancia de seguridad interpersonal de aproximadamente dos metros entre el cliente y el trabajador o entre los propios trabajadores.

4. Formación e información sobre el correcto uso de los equipos de protección.

5. El dispositivo de fichaje deberá desinfectarse antes y después de cada uso, advierto a los trabajadores de esta medida, incluso se sustituirá la huella dactilar por cualquier otro sistema de control de horario que garantice las medidas higiénicas adecuadas para la protección de la salud y de la seguridad de los trabajadores.

6.Modificación en la medida necesaria de la disposición de los puestos de trabajo, la organización de los turnos y el resto de las condiciones de trabajo, con la finalidad de garantizar la distancia de seguridad interpersonal mínima entre los trabajadores.

En el caso de que un trabajador pueda tener síntomas compatibles con la enfermedad, se contactará de inmediato con el teléfono habilitante y el trabajador deberá abandonar su puesto de trabajo hasta que su situación médica sea valorada por un profesional sanitario.

Con respecto a la clientela, las medidas serán las siguientes:

La distancia entre vendedor o proveedor de servicios y cliente durante todo el proceso de atención al cliente será al menos 1 metro cuando se cuente con elementos de protección o barreras, o de aproximadamente 2 metros sin estos elementos.

En el caso de que los servicios no permitan el mantenimiento de la distancia de seguridad interpersonal, como pueden ser las peluquerías, centros de estética o fisioterapia, se deberá utilizar el EPI oportuno que asegure la protección tanto del trabajador como del cliente, debiendo asegurar en todo caso el mantenimiento de la distancia de 2 metros entre un cliente y otro.

5 RDL 15/2020, de 21 de abril, de medidas urgentes complementarias para apoyar la economía y el empleo (BOE núm. 112, de 22 de abril).

6 Preámbulo II. MEDIDAS PARA REDUCIR LOS COSTES OPERATIVOS DE PYMES Y AUTÓNOMOS.

7 Una empresa o entidad pública de vivienda, o un gran tenedor, entendiendo por tal la persona física o jurídica que sea titular de más de 10 inmuebles urbanos, excluyendo garajes y trasteros, o una superficie construida de más de $1.500 \mathrm{~m}^{2}$. 
Los arrendatarios deben ser cualquier persona física o jurídica que reúna las condiciones de la Ley $\mathrm{N}^{\circ}$ 29/1994, de 24 de noviembre de arrendamiento urbanos (LAU) para uso distinto de vivienda o de industria.

Además, tengan la condición de autónomo o pymes ${ }^{8}$ siempre que cumplan ${ }^{9}$ y acrediten $^{10}$ una serie de requisitos. Téngase en cuenta que el arrendatario que habiendo obtenido el aplazamiento sin cumplir con los mismos será responsable de los daños y de los perjuicios que haya podido producir, así como los gastos generados por dicha aplicación, sin perjuicio de las responsabilidades que de otro orden pudieran lugar atribuible a dicha conducta.

Así pues, en el primer caso, el arrendatario podrá pedir al arrendador una moratoria en el pago de la renta mensual, a falta de acuerdo entre las partes sobre moratoria o reducción, durante el periodo de alarma y sus prórrogas sin que pueda superarse, en ningún caso, los cuatros meses. Se aplicará, en este caso, de manera automática e implicará un aplazamiento de la renta sin penalización ni devengo de intereses, a partir

\footnotetext{
8 En este caso parece que está excluyendo a toda organización que no tengan dicha condición, por lo que está restringiéndose el ámbito de aplicación a un colectivo en discriminación con otro en igual situación. Respecto a la definición de pyme se ha de observar el anexo I del Reglamento (UE) núm. 651/2014. Puede verse como ejemplo de pyme la sociedad de responsabilidad limitada y sus subtipos en Benito Osma, F. La sociedad de responsabilidad limitada, GPS Derecho de Sociedades, Tirant lo Blanch, Valencia, 2017, pp. 355-412.

9 1. En el caso de contrato de arrendamiento de un inmueble afecto a la actividad económica desarrollada por el autónomo: a) Estar afiliado y en situación de alta, en la fecha de la declaración del estado de alarma mediante el Real Decreto 463/2020, de 14 de marzo, por el que se declara el estado de alarma para la gestión de la situación de crisis sanitaria ocasionada por el COVID-19, en el Régimen Especial de la Seguridad Social de los Trabajadores por Cuenta Propia o Autónomos o en el Régimen Especial de la Seguridad Social de los Trabajadores del Mar o, en su caso, en una de las Mutualidades sustitutorias del RETA. b) Que su actividad haya quedado suspendida como consecuencia de la entrada en vigor del Real Decreto 463/2020, de 14 de marzo, o por órdenes dictadas por la Autoridad competente y las Autoridades competentes delegadas al amparo del referido real decreto. c) En el supuesto de que su actividad no se vea directamente suspendida como consecuencia de la entrada en vigor del Real Decreto 463/2020, de 14 de marzo, se deberá acreditar la reducción de la facturación del mes natural anterior al que se solicita el aplazamiento en, al menos, un 75 por ciento, en relación con la facturación media mensual del trimestre al que pertenece dicho mes referido al año anterior.

2. En caso de contrato de arrendamiento de inmueble afecto a la actividad económica desarrollada por una pyme: a) Que no se superen los límites establecidos en el artículo 257.1 del Real Decreto Legislativo 1/2010, de 2 de julio, por el que se aprueba el texto refundido de la Ley de Sociedades de Capital. b) Que su actividad haya quedado suspendida como consecuencia de la entrada en vigor del Real Decreto 463/2020, de 14 de marzo, o por órdenes dictadas por la Autoridad competente y las Autoridades competentes delegadas al amparo del referido real decreto. c) En el supuesto de que su actividad no se vea directamente suspendida en virtud de lo previsto en el Real Decreto 463/2020, de 14 de marzo, se deberá acreditar la reducción de su facturación del mes natural anterior al que se solicita el aplazamiento en, al menos, un 75 por ciento, en relación con la facturación media mensual del trimestre al que pertenece dicho mes referido al año anterior. 10 a) La reducción de actividad se acreditará inicialmente mediante la presentación de una declaración responsable en la que, en base a la información contable y de ingresos y gastos, se haga constar la reducción de la facturación mensual en, al menos, un 75 por ciento, en relación con la facturación media mensual del mismo trimestre del año anterior. En todo caso, cuando el arrendador lo requiera, el arrendatario tendrá que mostrar sus libros contables al arrendador para acreditar la reducción de la actividad. b) La suspensión de actividad, se acreditará mediante certificado expedido por la Agencia Estatal de la Administración Tributaria o el órgano competente de la Comunidad Autónoma, en su caso, sobre la base de la declaración de cese de actividad declarada por el interesado.
} 
de la siguiente mensualidad, mediante el fraccionamiento de las cuotas en un plazo de 2 años, siempre dentro de la vigencia del contrato o de cualquiera de sus prórrogas.

En el segundo supuesto, el arrendatario, en el plazo de un mes, podrá solicitar del arrendador el aplazamiento temporal y extraordinario del pago de la renta ${ }^{11}$, salvo que uno y otro no hubiera acordado con anterioridad el aplazamiento o una reducción de la renta.

Se prevé la posibilidad a las partes de poder disponer y servirse de la fianza al pago total o parcial de alguna de las mensualidades devengadas durante el estado de alarma, en cuyo caso el arrendatario debe reponer el importe de la misma en el plazo de un año desde la celebración del acuerdo o en el plazo que reste de la vigencia del contrato. Esta previsión se refiere exclusivamente al marco y supuestos que contempla la norma

\section{LOS REMEDIOS AL INCUMPLIMIENTO EN EL DERECHO Y EN LA JURISPRUDENCIA VIGENTE}

Con respecto a esta medida legislativa que entendemos que no tiene un carácter solutivo al problema por cuanto que diríamos que dichas atribuciones no le son propias, pero, sin embargo, arbitra los mecanismos preventivos y de continuidad de los contratos de arrendamiento de local de negocio suscritos vigentes.

Por ello, debemos hacer, en relación con la medida, las siguientes reflexiones, a falta de acuerdo entre las partes, sobre las normas vigentes generales y específicas, así como de la propia doctrina jurisprudencial aplicable en parecidos supuestos:

$1^{\text {a) }}$ El Art. 1.143 CC relativo al arrendamiento de cosas, una de las partes, se obliga a dar a la otra el goce o uso de una cosa por tiempo determinado y precio cierto. De tal modo, la situación de alarma impide a una de ellas el goce de la posesión del inmueble y que para la otra a cambio la obtención de un precio cierto; una equivalencia de las prestaciones, de tal modo que si una de las partes no cumple su obligación, la otra puede exigir su cumplimiento o resolver el contrato (Art. 1.124 CC).

$2^{\mathrm{a}}$ ) La declaración de estado de alarma ocasinada por la crisis sanitaria derivada de la pandemnia internacional supone un supuesto de fuerza mayor al que se refiere el Art. $1.105 \mathrm{CC}$ que no puede preverse o que, previsto, es inevitable.

$3^{\text {a }) ~ L a ~ i m p o s i b i l i d a d ~ d e ~ l a ~ p o s e s i o ́ n ~ p a c i ́ f i c a m e n t e ~ d e l ~ i n m u e b l e ~ o b j e t o ~ d e l ~ c o n t r a t o ~ s u-~}$ pone la paralización del plazo del arrendamiento y de la suspensión del pago de la renta. El Art. 26 de la LAU 29/94 ${ }^{12}$ para el arrendamiento de vivienda resulta aplicable igualmente para el de uso distinto de vivienda por aplicación de lo dispuesto en el Art. 30 de la LAU 29/94, siendo así que se trata de una regulación para el caso de que el inmueble

\footnotetext{
${ }_{11}$ Obsérvese que la norma no indica el periodo del aplazamiento temporal y extraordinario en el pago de la renta.

12 "Cuando la ejecución en la vivienda arrendada de obras de conservación o de obras acordadas por una autoridad competente la hagan inhabitable, tendrá el arrendatario la opción de suspender el contrato o de desistir del mismo sin indemnización alguna. La suspensión del contrato supondrá, hasta la finalización de las obras, la paralización del plazo del contrato y la suspensión de la obligación de pago de la renta”.
} 
no pueda destinarse al uso pactado por la realización de obras en la finca que la hagan inhabitable. Así se ha entendido, por ejemplo, la SAP de Barcelona, núm. 337/2018, de 25 de mayo; SAP de Pontevedra, núm. 375/2016, de 30 de junio, que admite la facultad del arrendatario de interesar la suspensión contractual (ex Art. 26 LAU).

$4^{\text {a }) ~ L a ~ i m p o s i b i l i d a d ~ d e l ~ u s o ~ d e l ~ i n m u e b l e, ~ a s i ́ ~ c o m o ~ d e ~ s u ~ e j e r c i c i o ~ e n ~ l a ~ a c t i v i d a d ~ p e r-~}$ mitida, para la cual se destina aquél resulta en este último equivalente con el derecho de disfrute de la cosa, lo que hace que desaparezca o se elimine totalmente no sólo el objeto sino la causa misma del contrato (Arts. 1.272 y 1.275 CC).

El contrato de arrendamiento de cosas tiene su fundamento en transmitir y mantener al arrendatario, por el arrendador, en el uso y goce pacífico de la cosa arrendada mientras dure el arrendamiento y en condiciones de ser utilizada al fin pactado (Arts. 1.554 y $1.555 \mathrm{CC}$ ), de modo que cuando el arrendador no puede cumplir su obligación esencial por la realización de una reparación acordada por la autoridad competente, el contrato puede suspenderse, cesando mientras tanto (mientras se realiza la obra) la obligación del arrendatario de pago de la renta. La regulación se completa con el Art. 1.558 del Código Civil que incluso contempla la facultad del arrendatario en el arrendamiento de vivienda de instar la resolución contractual por hacer "inhabitable la parte que el arrendatario y su familia necesitan para su habitación".

Este contrato de arrendamiento de local de negocio lo es de destino de la cosa a la actividad para la cual se estipuló inclusive en el propio contrato. Desde esta perspectiva, la pérdida de los elementos esenciales determinará la supensión ${ }^{13}$ e incluso la nulidad "per se" del contrato, siempre que sea alegada por alguna de las partes mientras permanezca la imposibilidad sobrevenida, produciéndose el perecimiento de las obligaciones contractuales; no a la razón del ejercicio de las facultades rescisorias ${ }^{14} \mathrm{o}$ resolutorias ${ }^{15}$ de las partes en el contrato

$5^{\text {a) }}$ La aplicación de la doctrina jurisprudencia de la "rebus sic stantibus 16 " (SSTS de 25 de marzo de 2013 y de 30 de junio de 2014), en relación con el Art. 7.1 CC y la doctrina de los actos propios sobre los requisitos exigidos por la mencionada jurisrpudencia para que la mutuación o cambio de circunstancias determine la desaparición de la base objetiva del negocio:

- la finalidad económica del contrato se frustre o se torne inalcanzable

- la conumutabilidad del contrato desaparezca prácticamente o se destruya, de suerte que no pueda hablarse de un juego entre la prestación y contraprestación

- $\quad$ el cambio o la mutación, configurado como riesgo, quede fuera del riesgo normal inherente a derivado del contrato.

\footnotetext{
13 Art. 26 LAU.

14 Arts. 1.556 y $1.558 \mathrm{CC}$.

15 Arts. 1.124 y $1290 \mathrm{CC}$

16 Benito Osma, F. "La excesiva onerosidad de las prestaciones en la contratación mercantil”, Estudios sobre el futuro Código Mercantil: libro homenaje al profesor Rafael Illescas Ortiz. Getafe: Universidad Carlos III de Madrid, 2015, pp. 1226-1231. ISBN 978-84-89315-79-2. http://hdl.handle.net/10016/21051.
} 
Por su parte, la STS 455/2019, de 18 de julio, es condición necesaria para su aplicación la imprevisibilidad del cambio de circunstancias para los contratantes, que por definición implica la no asunción del riesgo (STS de 5/2019, de 9 de enero) y que se da con mayor probabilidad en los contratos de larga duración, ordinariamente de tracto sucesivo y no en supuesto de contrato de corta duración, en el que difícilmente puede acaecer algo extraordinario que afecte a la base del contrato y no quede amparado dentro del riesgo propio de ese contrato (STS 791/2020, de 6 de marzo).

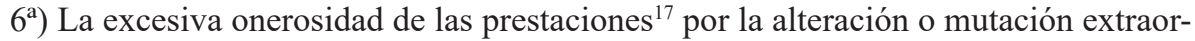
dinaria de las circunstancias y de las legítimas expectativas de las partes en el objeto de la base negocial del contrato; supone la imposibilidad sobrevenida del cumplimiento de la obligación y, a su vez, un desequilibrio negocial y desproporcionado de los intereses de las partes que permite, si fuera posible, la revisión o renegociación contractual y, cuando fuera imposible, la extinción de la obligación (Arts. $1.182 \mathrm{y}$ $1.184 \mathrm{CC})$.

\section{LAS CONSECUENCIAS DEL INCUMPLIMIENTO DEL PAGO DE LA RENTA DEL ARRENDATARIO}

El arrendador tendrá derecho al cumplimiento del contrato estipulado de arrendamiento de local de negocio, así como a las rentas impagadas vencidas actuales y futuras hasta el vencimiento del contrato (Arts. 1101 y 1124 CC).

Sin embargo, el arrendatario podrá sobre la base de los remedidos legales y jurisprudenciales referenciados alegar que no es posible el cumplimiento estricto y literal de las obligaciones del contrato de arrendamiento, pues su incumplimiento en el pago de la renta se debe a una causa externa sobrevenida e imprevisible que incluso deriva de una declaración gubernamental de estado de alarma por causa sanitaria que ha supuesto la suspensión y la interrupción del uso y del ejercicio de su actividad económica habitual y profesional. Por tanto, el arrendatario no puede cumplir con las obligaciones pactadas, adoptando posibles opciones al incumplimiento.

Una primera opción sería pretender el mantenimiento y conservación del negocio jurídico pactado, para que sea el juez quien modere y revise las rentas estipuladas en el contrato, a falta de acuerdo entre las partes, por las circunstancias formuladas anteriormente, con aplicación de los Arts. 1103, 1153 y 1154 CC. La segunda, no sería de continuidad contractual, sino de abandono, renuncia o de desistimiento del contrato de arrendamiento por la frustración de la causa del contrato, incluso la extinción de las obligaciones contractuales por pérdida de la cosa (Arts. 1156, 1182 y 1184 CC).

Generalmente, no se pacta la facultad unilateral de renuncia o desistimiento del contrato por el arrendatario, incluso en estas extraordinarias circunstancias. Téngase en

\footnotetext{
17 Benito Osma, F. "La excesiva onerosidad de las prestaciones en la contratación mercantil”, op. cit., pp. 1231-1234. También, puede verse en Perales Viscasillas, P. "La aplicación jurisprudencial de los principios de Unidroit", Miranda Serrano, L y Pagador López, J. Retos y tendencias del Derecho de la contratación mercantil, Marcial Pons, 2017, pp. 821-824.
} 
cuenta que el arrendatario perderá los derechos que, sin embargo, la LAU (Art. 11) reconoce dicha facultad de desistimiento para el arrendatario de vivienda. En este caso, las partes pueden pactar que el arrendatario indemnice al arrendador con una cantidad equivalente a una mensualidad de la renta en vigor por cada año del contrato que reste por cumplir. Los períodos de tiempo inferiores al año darán lugar a la parte proporcional de la indemnización.

Esta facultad no es reconocida legalmente al arrendatario de local de negocio por la LAU, lo que no significa que no pueda estipularse la misma de acuerdo con el principio de la autonomía de la voluntad (Art. $1255 \mathrm{CC}$ ). Y, en el caso de que así se establezca, será posible que sea modere atendiendo a las circunstancias teniendo en cuenta el criterio orientativo de la $\mathrm{LAU}^{18}$. Para el caso de que el arrendatario opte por el desistimiento resulta necesario algo más que el silencio o la no recepción de las llaves para considerar aceptada la renuncia unilateral ${ }^{19}$.

La aceptación en su caso del arrendador plantea dos escenarios consecuenciales sobre la pérdida o mantenimiento de los legítimos derechos de uno y otro -arrendador y arrendatario- en caso de término anticipado del contrato de arrendamiento de local de negocio. Para el arrendador la pérdida de las rentas adeudas vencidas y aquellas otras futuras hasta la fecha del cumplimiento del contrato, así como otras cláusulas penales establecidas. Para el arrendatario la indemnización correspondiente por los daños y perjuicios a consecuencia de la pérdida/interrupción del negocio y de la clientela (Art. 34 LAU) al término del plazo contractual cuando el inquilino manifiesta su voluntad inequívoca en la continuidad o renovación del contrato de acuerdo por el mismo término de 5 años y por una renta conforme al valor de mercado.

\section{LOS SEGUROS EN LOS CONTRATOS DE ARRENDAMIENTO DE LOCAL DE NEGOCIO}

En este punto, sobre el impacto que tiene la pandemia y sus efectos sobre los seguros vinculados con el contrato de arrendamiento de local de negocio que se estipulan e imponen por el arrendador al arrendatario en el mismo. Como se ha apuntado anteriormente con las medidas legales, la moratoria y el aplazamiento extraordinario venían referido al pago de la renta del arrendatario, pero no respecto a otros gastos, como las primas de seguro multirriesgo de los autónomos y de las pymes arrendatarias, presentes y futuras, es decir, ¿el arrendatario del local de negocio tendrá derecho a solicitar la devolución o reintegro de las primas no consumidas a su asegurador du-

\footnotetext{
18 Tribunal Supremo (Sala de lo Civil), sentencia núm. 42/2016 de 11 febrero (RJ 2016 551 ). Audiencia Provincial de Barcelona, sección 13aa , sentencia núm. 313/2016 de 23 junio (JUR 2016\197219).

19 Tribunal Supremo (Sala de lo Civil), sentencia núm. 481/2018, de 23 de julio: "Es más, de acuerdo con la jurisprudencia de esta sala, sería necesario algo más que el silencio o la no recepción de las llaves, para considerar aceptada la resolución unilateral en este sentido, sentencia 571/2013, de 27 de septiembre, recurso 959/2011. En conclusión, al no haberse pactado el desistimiento unilateral del arrendatario, ni aceptado el mismo por el arrendador procede la estimación la acción de cumplimiento del contrato con condena al pago de las rentas pendientes, en la forma solicitada en la demanda y en el recurso de casación".
} 
rante la suspensión o cese de su actividad durante la vigencia de la póliza?, ¿y frente al arrendador?; lo mismo nos preguntamos respecto a si el tomador/asegurado/arrendatario tiene la facultad de suspensión de la póliza de seguros y de la oponibilidad a la prórroga del seguro transcurrido el plazo legal de oposición y, en caso contrario, a la reducción de la prima sobrevenida renovada conforme a los principios de la técnica aseguradora y de los principios, elementos esenciales y cargas en el contrato de seguro, específicamente contempladas dichas facultades en los Arts. 13 y 22 LCS.

Las obligaciones de las partes en el contrato, a falta de acuerdo, quedan suspendidas durante el periodo de alarma y de sus prórrogas ${ }^{20}$. Cuando se establece en el contrato la obligación para el arrendatario de contratación de un seguro contra daños, en tanto que la declaración del estado de alarma genera para él la paralización e interrupción $\mathrm{y}$, en su caso, el cese de la actividad quedará sin efecto, máxime en el caso de cese total de la actividad. En este caso, el arrendatario tendrá diversas opciones, una es la vía de solicitar a la entidad aseguradora la prima no consumida y de otra imputar al arrendador tal gasto, en tanto que el arrendatario no ostenta el uso y goce de la cosa objeto de arrendamiento durante este periodo excepcional y temporal.

Independientemente de este tipo de seguros contra daños vinculados al contenido del inmueble, puede contemplarse otros riesgos inherentes a la actividad comercial e industrial del arrendatario que se conocen como pólizas multirriesgo empresarial, que generalmente excluyen los daños por interrupción de empresa, circunstancia distinta será que los arrendatarios puedan solicitar la cobertura por daños materiales consecuenciales directos provenientes de un daño material cubierto (p. ej. pérdida de alqui$\operatorname{ler}^{21}$ ) que deriva de un hecho no excluido expresamente en la póliza de seguro como resulta con la pandemia asociada a la declaración de estada de alarma sanitaria.

\section{¿Cómo afectará en el seguro de impago de arrendamientos de local de negocio?}

El objeto del seguro de impago de alquiler es ofrecer cobertura a los gastos y perjuicios económicos derivados del impago de la renta por parte del inquilino o arrendatario, así como de los perjuicios materiales que este pueda causar en el continente de la vivienda o local dentro de los límites establecidos y de las exclusiones contenidas en el propio contrato. Uno de ellos, es que el impago sea de al menos tres meses y uno de ellos sea durante el periodo de vigencia de la póliza y que el deudor no sea insolvente

\footnotetext{
${ }_{20}$ Art. 955 CdC: "En los casos de guerra, epidemia oficialmente declarada o revolución, el Gobierno podrá, acordándolo en Consejo de Ministros y dando cuenta a las Cortes, suspender la acción de los plazos señalados por este Código para los efectos de las operaciones mercantiles, determinando los puntos o plazas donde estime conveniente la suspensión, cuando ésta no haya de ser general en todo el Reino". Y, por otro lado, quedan suspendidos los plazos de prescripción y de caducidad de acuerdo con la DA 4 ${ }^{\text {a RD }}$ 463/2020. 21 Tirado SuÁRez, F.J., "Seguros de lucro cesante y responsabilidad civil”, JimÉnez SÁnchez, G y DíAz Moreno, A., Derecho Mercantil. Los contratos de seguro, vol. 9º $15^{\mathrm{a}}$ ed., Marcial Pons, 2013, p. 190: "El titular del interés puede ser tanto el propietario o arrendador como el arrendatario. El arrendador será indemnizado de la pérdida de los alquileres no debidos (Art. $1563 \mathrm{CC}$ ), mientras que el arrendatario es garantizado contra el pago de alquileres debidos al arrendador, aunque si el nexo causal del que deriva la pérdida de alquiler no es imputable a la esfera jurídica del arrendatario, no debe existir el deber de pago".
} 
según declaración judicial. Con respecto a la exclusión general de póliza asimilable al COVID-19 es la denominada "catástrofe o calamidad nacional".

También, debemos hacer las connotaciones respecto al interés asegurado y el concepto por el cual se asegura, es decir, quien será el tomador y el asegurado en este tipo de pólizas, cuando precisamente pueden preverse en el contrato garantías adicionales con el objeto de garantizar el cumplimiento por los arrendatarios de las obligaciones arrendaticias mediante pólizas de seguro de protección de pagos de arrendamientos. Igualmente, es factible la figura del beneficiario por designación del tomador de seguro. Generalmente, habrá coincidencia de tomador y asegurado (propietario/arrendador o arrendatario), en cuyo caso será beneficiario irrevocable el propietario en el caso de contratación por el arrendatario.

La suscripción de estos seguros está supeditada al aporte por el arrendatario de datos actualizados de su solvencia y de estudios de viabilidad en el momento de la firma del contrato de arrendamiento.

En el caso de que el arrendatario de local de negocio se acoja a cualquiera de las medidas legales (mora o aplazamiento del pago de la renta), debe reflexionarse sobre si tales remedios son objeto de cobertura y en caso afirmativo cuál sería su alcance. Y, por otro lado, los mismos interrogantes en el caso de acuerdo o pacto de reducción del precio de la renta. En cualquiera de los dos supuestos se garantiza por el asegurador los gastos de defensa de reclamación o transacción por vía amistosa, en ningún caso las pérdidas a consecuencia de la aplicación de tales remedios al incumplimiento/ impago de la renta del arrendatario.

\section{EL AVAL BANCARIO}

Las partes pueden pactar contractual y adicionalmente a la fianza cualquier tipo de garantía en el cumplimiento por el arrendatario de sus obligaciones arrendaticias. Desde esta perspectiva, el aval bancario constituye una garantía adicional financiera dispuesta al cumplimiento de las obligaciones del arrendatario equivalente generalmente a un año de renta del contrato que es incorporado en el contrato con la aceptación de entrega del mismo.

La característica del aval a primer requerimiento es la de dar nacimiento a una obligación de garantía inmediata, que pierde su carácter accesorio de la obligación principal, en el que la obligación del garante es independiente de la obligación del garantizado y del contrato inicial (sentencias 735/2005, de 27 de septiembre; 979/2007, de 1 de octubre; y 671/2010, de 26 de octubre). Pero sin que impida el ejercicio de las acciones que puedan surgir a consecuencia del pago de la garantía (sentencias 1057/2001, de 14 de noviembre; y 697/2002, de 5 de julio) o para determinar el grado de cumplimiento de la obligación principal garantizada. No es necesario demostrar el incumplimiento de la obligación garantizada sino que basta con la reclamación del deudor para hacer efectivo el cumplimiento de ésta (SSTS de 11 de julio de 1983, 14 de noviembre de 1989, 2 de octubre de 1990, 27 de octubre de 1992, 3 de mayo de 1999, 10 de no- 
viembre de 1999, 17 de febrero de 2000, 30 de marzo de 2000, 5 de julio de 2000, 13 de diciembre de 2000, 12 de julio de 2001, 14 de noviembre de 2001, 29 de abril de 2002, 5 de julio de 2002, 31 de mayo de 2003, 12 de noviembre de 2003, 28 de mayo de 2004, 27 de septiembre de 2005, y 9 de diciembre de 2005).

Como señala la STS, Sala de lo Civil, núm. 217/2019, de 5 de abril:

\begin{abstract}
"Una de las notas diferenciales de la fianza es que bastará con la reclamación sin que sea preciso demostrar el incumplimiento de la obligación garantizada A diferencia de lo que sucede con la fianza ordinaria (según la sentencia 81/2014, de 4 de marzo, el aval a primer requerimiento es una fianza con determinadas especialidades), no se requiere el incumplimiento de la obligación principal, ya que estas garantías pueden ser hechas efectivas a simple requerimiento. En las sentencias 81/2014, de 4 de marzo, 330/2016, de 19 de mayo, y 679/2016, de 21 de noviembre, hemos resaltado que una de las notas características que diferencian el aval a primer requerimiento de la fianza regulada en el Código Civil es su no accesoriedad, por lo que para la efectividad de la garantía no es preciso demostrar el incumplimiento de la obligación garantizada, sino que para hacer efectivo el cumplimiento de esta bastará con la reclamación del deudor. Así como que el garante no puede oponer al beneficiario que reclama el pago otras excepciones que las que se deriven de la garantía misma, pues lo contrario supondría desvirtuarla naturaleza de esta obligación".
\end{abstract}

\title{
7. LAS CLÁUSULAS PENALES
}

Aparte de las garantías adicionales financieras referenciadas, resulta factible en este tipo de contratos el establecimiento de cláusulas penales porcentuales y graduales incorporadas contractualmente (Art. $1255 \mathrm{CC}$ ) aplicables en caso de incumplimiento del plazo de duración del contrato (resolución anticipada), así como en el caso de incumplimiento total o tardío en el pago de la renta.

Su incorporación en el contrato cumple una función coercitiva en el cumplimiento de las obligaciones por el arrendatario (Arts. 1091 y 1152 CC) y, a su vez, otra liquidadora de los daños y perjuicios que haya podido provocar el incumplimiento o el cumplimiento defectuoso de la obligación (Art. $1153 \mathrm{CC})^{22}$. No impide que sea acumulativa de aquellas otras pactadas expresa y justificadamente indemnizatorias. Como señala la STS, Sala de lo Civil, núm. 74/2018, de 14 de febrero, la cláusula penal pactada por las partes era una pena que no excluía que se reclamaran daños que se produjeran por el incumplimiento. La pena no se dirigía a liquidar de manera anticipada los daños que pudieran causar los incumplimientos; era exigible una vez que se produjera el incum-

\footnotetext{
22 El Tribunal Supremo (Sala de lo Civil), sentencias núms. 530/2016, de 13 de septiembre, 44/2017, de 25 de enero y 126/2017, de 24 de febrero, salvo en condiciones generales de la contratación entre empresarios y consumidores (Art. 85.6 de la Ley general para la defensa de los consumidores y usuarios), nuestro Derecho permite las cláusulas penales con función coercitiva, sancionadora o punitiva: no sólo de liquidación anticipada de los daños y perjuicios que puedan causar los incumplimientos contractuales por ellas contemplados. Se permiten incluso en el Art. 1152.I CC («si otra cosa no se hubiere pactado») las penas que no sustituyen, sino que se acumulan a la indemnización de daños y perjuicios (por todas, sentencia 197/2016, de 30 de marzo).
} 
plimiento para el que se pactó, con independencia de la acreditación de esos daños. Era improcedente, por tanto, su moderación hasta el punto de eliminar su aplicación por entender que no ha habido daños indemnizables, reforzando así su argumento de la nulidad.

\section{CONSIDERACIONES FINALES}

La crisis sanitaria derivada del COVID-19 ha provocado la declaración de estado de alarma y de emergencia sanitaria por salud pública, a causa de la declaración internacional por la (OMS) de "pandemia-COVID-19",

Las consecuencias derivadas de ambas situaciones ha supuesto especialmente para las pequeñas y medianas empresas con arrendamientos de local de negocio un escenario brutal de deterioro económico y financiero con la imposibilidad total o parcial sobrevenida del uso y del goce pacífico del local como instrumento del ejercicio y de la continuidad de la actividad empresarial propia habitual, principalmente por las medidas restrictivas de cierre, suspensión e interrupción temporal de actividades no esenciales, así como de una total y consecuencial incertidumbre e inseguridad jurídica, por y a pesar del RDL 15/2015, de 21 de abril, de medidas urgentes complementarias para apoyar a la economía y el empleo.

La reacción del ejecutivo y posteriormente del legislativo ha sido establecer un régimen diferente para el caso arrendamientos de local de negocio destinado a arrendatarios autónomos y pymes con arrendadores grandes tenedores, a los que se aplicará una moratoria automática sin intereses ni penalizaciones mientras que, para el resto, un aplazamiento temporal y extraordinario, sin plazo preestablecido, pero sí, en el caso de moratoria automática, durante el estado de alarma y de sus prórrogas y a las mensualidades siguientes, prorrogables una a una, si aquel plazo fuera insuficiente en relación con el impacto provocado por el COVID-19, sin que puedan superarse, en ningún caso, los cuatro meses. Nada dice el RDL 15/2015 sobre la facultad de desistimiento del arrendatario de local de negocio, sí prevista legamente para los arrendamientos de vivienda (Art. 11 LAU).

Esta facultad no se encuentra prevista generalmente en los contratos de arrendamiento de local de negocio, entendemos que no existe óbice alguno en que éste pueda solicitarlo y sea aceptado expresa o tácitamente por el arrendador, circunstancia distinta será la liberación o moderación de las cláusulas penales por incumplimiento de las rentas impagadas y de aquellas otras hasta el vencimiento del contrato de arrendamiento. El arrendatario queda privado de su interés por tales circunstancias de hecho y de derecho en el uso y goce del local que constituía el instrumento esencial para el ejercicio de su actividad económica.

Ello significa que, a falta de pacto entre las partes sobre el aplazamiento o disminución del precio del arrendamiento, dichas medidas establecidas en el RDL 15/2020 serán las aplicables, por lo que, en tales situaciones, el arrendatario tendrá que solicitar la moratoria automática en el primer supuesto y, en el segundo, el aplazamiento extraor- 
dinario, con el fin de evitar perjuicios directos e indirectos al avalista o al fiador en el cumplimiento del contrato de arrendamiento objeto de garantía adicional contractual.

El RDL 15/2015 nada dice sobre las consecuencias de tales medidas en las garantías adicionales contractualmente preestablecidas en los contratos de arrendamiento de local de negocio (avales a primer requerimiento, fiadores y seguros). Sí, respecto a las fianzas, que podrán las partes disponer de ellas y servir de pago total o parcial de las rentas, debiéndose reponer aquellas en un plazo de un año.

Con respecto a los seguros, habría que hacer una serie de distinciones respecto al seguro multirriesgo de empresa y de aquel otro seguro en protección de impago de alquileres de local de negocio. En el primero de ellos, posiblemente pueda pretenderse que la aseguradora se haga cargo de las consecuencias del impago del alquiler, siempre y cuando su causa derive de un hecho cubierto en la póliza como daño material específico -la inhabilitación del local ${ }^{23}$, siempre que no se encuentre excluido expresamente en la póliza (pandemia). Y, por otro lado, el seguro de impago de alquiler que garantiza la prestación de un servicio y de la cobertura de los daños materiales equivalente a las rentas reclamadas dentro de los límites establecidos en la póliza, si bien quedando presente las cláusulas de exclusión generalmente introducidas en las pólizas de este tipo referidas a los calificados por las autoridades gubernativas como de "catástrofe o calamidad nacional".

Los interrogantes sobre este último tipo de pólizas se ciernen, aparte de la exclusión, también con el titular del interés asegurado, el pago de las primas, especialmente en los seguros por cuenta ajena y si durante estos momentos de pandemia nos encontramos con circunstancias de agravación del riesgo para las pólizas contratadas y de las futuras.

\section{BIBLIOGRAFÍA}

Benito Osma F. "La excesiva onerosidad de las prestaciones en la contratación mercantil", Estudios sobre el futuro Código Mercantil: libro homenaje al profesor Rafael Illescas Ortiz. Getafe: Universidad Carlos III de Madrid, 2015.

\footnotetext{
${ }^{23}$ Téngase en cuenta el RDL 15/2015. Preámbulo II. MEDIDAS PARA REDUCIR LOS COSTES OPERATIVOS DE PYMES Y AUTÓNOMOS: “A falta de acuerdo entre las partes, la Ley N²9/1994, de 24 de noviembre, de Arrendamientos Urbanos no prevé causa alguna de exclusión del pago de la renta por fuerza mayor o por declaración de estado de alarma u otras causas, salvo en lo referido en su artículo 26, relativo a la habitabilidad de la vivienda derivada de la ejecución de obras, que puede ser aplicable a los locales de negocio vía artículo 30 de esta Ley.

Asimismo, si se acude a la regulación del Código Civil referida a la fuerza mayor, tampoco ofrece una solución idónea porque no ajusta la distribución del riesgo entre las partes, aunque puede justificar la resolución contractual en los casos más graves.

Ante esta situación, procede prever una regulación específica en línea con la cláusula rebus sic stantibus, de elaboración jurisprudencial, que permite la modulación o modificación de las obligaciones contractuales si concurren los requisitos exigidos: imprevisibilidad e inevitabilidad del riesgo derivado, excesiva onerosidad de la prestación debida y buena fe contractual.

Se considera conveniente ofrecer una respuesta que permita abordar esta situación y regular un procedimiento para que las partes puedan llegar a un acuerdo para la modulación del pago de las rentas de los alquileres de locales".
} 
Benito Osma F. "La sociedad de responsabilidad limitada", GPS Derecho de Sociedades, Tirant lo Blanch, Valencia, 2017.

Perales Viscasillas, P. "La aplicación jurisprudencial de los principios de Unidroit”, Miranda Serrano, L. y Pagador López, J. (Dir.). Retos y tendencias del Derecho de la contratación mercantil, Marcial Pons, 2017.

Tirado Suárez, F. J. "Seguros de lucro cesante y responsabilidad civil”. JimÉnez Sánchez, G. y Díaz Moreno, A. Derecho Mercantil. Los contratos de seguro, vol. $9^{\circ}, 15^{\mathrm{a}}$ ed., Marcial Pons, 2013. 
